\title{
Hepatitis $A$ and hepatitis $B$ vaccination responses in persons with chronic hepatitis $C$ infections: A review of the evidence and current recommendations
}

\author{
Jane A Buxton MBBS $\mathrm{MHSc}^{1,2}$, Jin Hee Kim MD BSc${ }^{1}$
}

JA Buxton, JH Kim. Hepatitis A and hepatitis B vaccination responses in persons with chronic hepatitis $\mathrm{C}$ infections: $\mathrm{A}$ review of the evidence and current recommendations. Can J Infect Dis Med Microbiol 2008;19(2):197-202.

In persons with chronic hepatitis $\mathrm{C}$ virus (HCV) infections, superinfection by hepatitis A virus (HAV) or hepatitis B virus (HBV) can cause serious complications, including fulminating hepatitis or increased severity of hepatitis. Therefore, it is important to adequately protect persons with chronic HCV infections by immunization. Suboptimal response to vaccines has been reported in patients with chronic liver disease. The present article reviews HAV and HBV vaccine responses reported in the literature when administered to individuals with chronic HCV infection, and reviews current national and international recommendations.

RESULTS: Persons with chronic HCV respond well to HAV vaccine, but studies exploring HBV vaccine efficacy in this population have equivocal results. Vaccine schedules and participant characteristics differ among studies, and most do not adjust for confounders. Some studies found no difference in HBV vaccine response between patients with chronic $\mathrm{HCV}$ and controls. However, HBV vaccine response was generally reduced in those with cirrhosis and HCV genotype 1. Organizations recommend HAV and HBV vaccines for persons with chronic HCV, but do not suggest alterations in schedule or dose.

RECOMMENDATIONS: Because HAV vaccine response is good and routine laboratory testing may not detect lower levels of vaccineinduced anti-HAV, the standard HAV vaccine schedule is recommended without postimmunization testing. HBV vaccine should be administered early in the course of chronic HCV infection because response may be lower in patients with cirrhosis. Reflex testing of anti-HCV reactive sera for anti-HAV and hepatitis B surface antibody can facilitate appropriate follow-up and timely immunization. Determination of postimmunization hepatitis B surface antibody, especially in patients with cirrhosis or genotype 1, will allow HBV vaccine boosters to be offered.

Key Words: Hepatitis A virus; Hepatitis B virus; Hepatitis C virus; Immunization; Vaccine efficacy
Les réponses des vaccins contre l'hépatite $\mathrm{A}$ et l'hépatite $\mathrm{C}$ chez les personnes atteintes d'une infection chronique par l'hépatite $\mathrm{C}$ : Une analyse des données probantes et des recommandations courantes

Chez les personnes atteintes d'une infection chronique par le virus de l'hépatite C (VHC), une superinfection par le virus de l'hépatite A (VHA) ou le virus de l'hépatite B (VHB) peut provoquer de graves complications, y compris une hépatite fulminante ou une aggravation de l'hépatite. Il est donc important de vacciner les personnes atteintes d'une infection chronique par le VHC pour bien les protéger. On a remarqué des réponses sous-optimales aux vaccins chez les personnes atteintes d'une maladie hépatique chronique. Le présent article analyse les réponses aux vaccins contre le VHA et le VHB déclarées dans les publications lorsqu'ils sont administrés à des personnes atteintes d'une infection chronique par le VHC, de même que les recommandations nationales et internationales courantes.

RÉSULTATS : Les personnes atteintes d'un VHC chronique répondent bien au vaccin contre le VAH, mais les études portant sur l'efficacité du vaccin contre le VHB au sein de cette population ont donné des résultats équivoques. Le calendrier de vaccination et les caractéristiques des patients diffèrent selon les études, et la plupart ne contiennent pas de rajustement tenant compte des variables confusionnelles. Certaines études ne constatent aucune différence dans la réaction au vaccin contre le VHB entre les personnes atteintes d'un VHC chronique et les sujets témoins. Cependant, en général, la réponse au vaccin contre le VHB était réduite chez les personnes atteintes de cirrhose et du VHC de génotype 1. Les organisations recommandent de vacciner les personnes atteintes d'un VHC chronique contre le VHA et le VHB, mais elles ne proposent pas de modifier le calendrier ou la dose de vaccination.

RECOMMANDATIONS : Puisque la réponse au vaccin contre le VHA est bonne et que les tests de laboratoire habituels ne permettent peut-être pas de déceler les taux plus faibles d'anti-VHA induits par le vaccin, le calendrier habituel de vaccination contre le VHA est recommandé, sans tests postvaccination. Il faut administrer le vaccin contre le VHB rapidement dans l'évolution de l'infection chroniqu par le VHC, car la réponse peut être plus faible chez les patients cirrhotiques. Le test réflexe du sérum réactif anti-VHC de l'anti-VHA et de l'anticorps de surface de l'hépatite B peut favoriser un suivi convenable et une vaccination au moment opportun. La détermination de l'anticorps de surface contre l'hépatite $B$ après la vaccination, notamment chez les patients cirrhotiques ou atteints du génotype 1 , permettra d'offrir des doses de rappel du vaccin contre le VHB.

liver disease and hepatocellular carcinoma. The most common risk factor for newly acquired HCV infection in Canada is through illicit drug use (1).

Higher rates of serious complications from acute infection with hepatitis A virus (HAV), such as fulminating hepatitis,
$\mathrm{H}$ epatitis $\mathrm{C}$ virus (HCV) is an RNA virus that chronically affects 170 million people worldwide. Of those infected, $70 \%$ to $80 \%$ become chronically infected (ie, they do not clear the virus, which can be detected by HCV-RNA testing). Chronic HCV infection may progress to cirrhosis, end-stage

${ }^{1}$ BC Centre for Disease Control; ${ }^{2}$ Department of Health Care and Epidemiology, University of British Columbia, Vancouver, British Columbia

Correspondence: Dr Jane A Buxton, BC Centre for Disease Control, 655 West 12th Avenue, Vancouver, British Columbia V5Z 4 R4.

Telephone 604-660-6061, fax 604-660-0197, e-mail jbuxton@interchange.ubc.ca

Received for publication August 13, 2007. Accepted November 26, 2007 
TABLE 1

Hepatitis A virus (HAV) vaccine response in persons with hepatitis C virus (HCV) infection

\begin{tabular}{lcllll}
\hline Author (ref), site(s) & Year published & Subjects & Vaccine schedule & Results in chronic HCV & Results in controls \\
\hline Keeffe et al (14), & 1998 & 104 anti-HCV reactive & 1440 ELU of Havrix* & $94 \%$ HAV scv at 7 months & $98 \%$ HAV scV at 7 months \\
$\begin{array}{l}4 \text { United States } \\
\text { 4 European }\end{array}$ & & 188 controls & 0,6 months & & \\
\hline
\end{tabular}

Seroconversion (scv) for anti-HAV greater than or equal to $33 \mathrm{mIU} / \mathrm{mL}$. *GlaxoSmithKline, USA. ELU ELISA units; ref Reference

have been reported in patients with chronic liver disease, including chronic HCV infection (2). Inactivated HAV vaccine has been available in Canada since 1994. The two-dose series, with the second dose administered six to 18 months following the first, has been found to be highly immunogenic, producing protective antibody levels in over $94 \%$ of all individuals after the first dose and in 100\% following the second dose in immunocompetent individuals. Reduced immunogenicity has been reported in immunocompromised individuals (3).

Policies on HAV vaccination focus on three key populations at risk of HAV - people in or travelling to endemic areas, populations at higher risk of acquiring HAV, and populations at higher risk of severe HAV disease, which includes those with $\mathrm{HCV}$ infection. Routine post-HAV immunization serology is not recommended because the immune response to the vaccine is excellent and the standard laboratory antibody tests used to identify HAV infection may not detect vaccine-induced antibodies, which may be lower than the threshold of detection.

Although in some studies, superinfection of hepatitis B virus (HBV) and HCV has been found to suppress the level of replication of the other virus, in others, superinfection of HBV has been found to enhance the severity of hepatitis and the risk of developing liver cirrhosis and hepatocellular carcinoma in patients with chronic HCV infection $(4,5)$. The prevalence of $\mathrm{HCV}$ in intravenous drug users is high (65\% to $92 \%)(6,7)$; transmission of HBV may be through intravenous drug use or may be sexually transmitted. Therefore, it is important that persons with chronic HCV are protected against HBV infection.

HBV vaccine has been licensed in Canada since 1982. It is highly efficacious in preventing clinical and subclinical infections in the vast majority of healthy people with $10 \mu \mathrm{g}$ or $20 \mu \mathrm{g}$ of recombinant hepatitis B surface antigen ( $\mathrm{HBsAg}$ ) administered at zero, one and six months. Decreased efficacy has been associated with smoking, increased age, obesity, alcoholism, immunocompromising chronic disease, patients receiving hemodialysis, those with HIV infection and certain human leukocyte antigen types or haplotypes (8-11).

Studies of vaccination safety have shown that both HAV and HBV vaccines are safe in patients with chronic HCV infection. However, suboptimal response is reported with HBV vaccine in patients with chronic liver disease, but studies on efficacy specific to chronic HCV infection have yielded equivocal results $(12,13)$. Physicians, public health nurses and hepatitis advocacy groups frequently pose questions about the vaccine schedules and the need for postimmunization serology. The aim of the present article was to:

- Review current literature regarding efficacy of HAV and $\mathrm{HBV}$ vaccine in individuals with chronic $\mathrm{HCV}$ infection;

- Review national and international recommendations regarding HAV and HBV vaccine in individuals with chronic HCV infection; and
- To make evidence-based recommendations for HAV and $\mathrm{HBV}$ vaccine in individuals with chronic HCV infection.

\section{METHODS}

The MEDLINE database was searched for relevant publications between 1966 and 2007. MeSH terms included - hepatitis C, immunization, vaccine, hepatitis A and hepatitis B. Studies with less than 20 anti-HCV subjects were excluded. All studies identifying anti-HCV reactive subjects were included. Primary and follow-up studies were reviewed to ensure that full details of the initial study subjects' responses were collected. The HAV and HBV immunization recommendations for persons with HCV from the World Health Organization (WHO), the United States Advisory Committee on Immunization Practices (ACIP), the American Association for the Study of Liver Diseases and the Canadian National Advisory Committee on Immunization, were reviewed.

\section{HAV vaccination}

\section{RESULTS}

The results of the literature review are summarized in Table 1. Although two prospective studies $(14,15)$ were found that looked at the efficacy of the HAV vaccine for the HCVpositive population, the second study by Lee et al (15) was excluded because only four persons with HCV were included. Keeffe et al (14) compared HAV seroconversion rates of anti$\mathrm{HCV}$-positive patients and other chronic liver disease patients against a group of healthy controls. Seroconversion was defined as seropositive for anti-HAV greater than or equal to $33 \mathrm{mIU} / \mathrm{mL}$. A significantly higher proportion of healthy subjects had seroconverted one month after a single dose of HAV vaccine (93\% of 185 individuals) compared with chronic HCV subjects (73.7\% of 99 individuals). Healthy controls had a statistically significant higher geometric mean anti-HAV concentration compared with HCV-positive subjects (175 mIU/mL versus $77 \mathrm{mIU} / \mathrm{mL}$, respectively). However, one month after the second dose of HAV vaccine, there was no significant difference in the rate of seroconversion between the two groups (98.2\% of healthy individuals and $94.5 \%$ of those with chronic $\mathrm{HCV}$ ), and the geometric mean anti-HAV concentrations of $1315 \mathrm{mIU} / \mathrm{mL}$ in healthy controls and $467 \mathrm{mIU} / \mathrm{mL}$ (95\% CI $345 \mathrm{mIU} / \mathrm{mL}$ to $631 \mathrm{mIU} / \mathrm{mL}$ ) in persons with chronic HCV infection.

Both the WHO and the American Association for the Study of Liver Diseases recommend HAV vaccine for people with chronic HCV infection without specifying an altered dose or schedule (16). The United States ACIP cites lack of evidence for vaccinating against HAV on the basis of chronic HCV alone, but recommends that HAV-susceptible persons who are either awaiting or have received liver transplants, or in whom there is evidence of chronic liver disease, should be vaccinated (17). 
TABLE 2

Hepatitis B vaccine response in persons with hepatitis C virus (HCV) infection

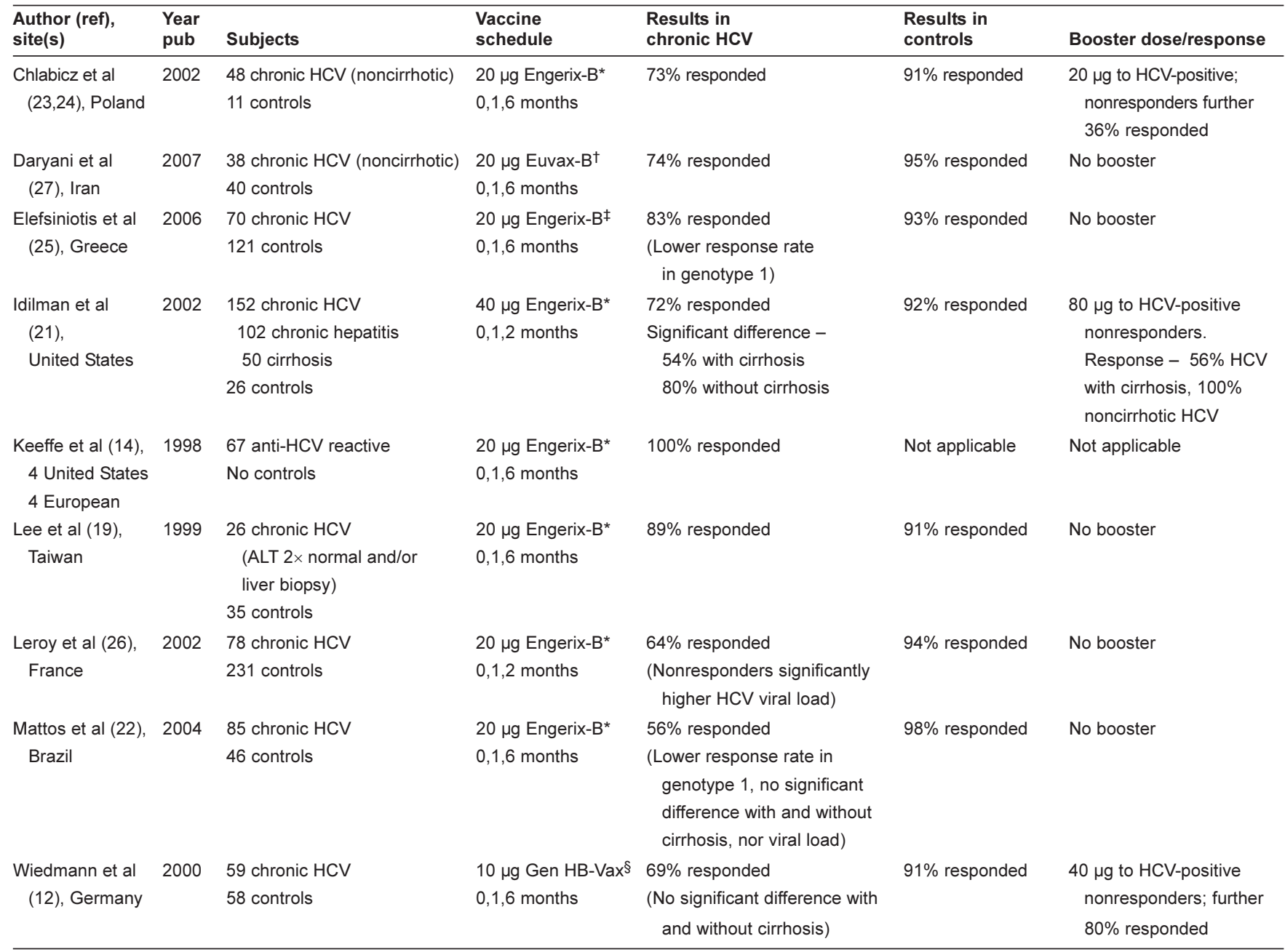

Responded: Postvaccine antibody to the hepatitis B surface antigen greater than or equal to $10 \mathrm{mIU} / \mathrm{mL} .{ }^{*} \mathrm{SmithKline} \mathrm{Beecham} \mathrm{Biologicals,} \mathrm{Belgium;}{ }^{\dagger} \mathrm{LG}$ Chem, Korea; ¥GlaxoSmithKline, USA; §Chiron-Behring Division, Pasteur Mérieux MSD, Germany. ALT Alanine aminotransferase; ref Reference; Year pub Year published

The Canadian Immunization Guide (18) recommends HAV vaccine for persons with chronic liver disease including persons infected with HCV who may not be at increased risk of infection, but who are at increased risk of fulminant hepatitis A. No modifications to the standard vaccination schedule are recommended for patients with $\mathrm{HCV}$ receiving HAV vaccine by any of the sources reviewed.

\section{$\mathrm{HBV}$ vaccination}

Since the late 1990s, several prospective trials have studied the immunogenicity of $\mathrm{HBV}$ vaccine in individuals with chronic $\mathrm{HCV}$ infection. The terms seroprotection and seroconversion were used inconsistently in the literature to classify the level of antibody to the hepatitis B surface antigen (anti-HBs); it is usually measured one to six months after the immunization series is completed. The Canadian Immunization Guide defines HBV seroprotection as anti-HBs greater than or equal to $10 \mathrm{mIU} / \mathrm{mL}$. In the present paper, those who have anti-HBs greater than or equal to $10 \mathrm{mIU} / \mathrm{mL}$ are referred to as $\mathrm{HBV}$ vaccine responders. The literature review is summarized in Table 2.

Keeffe et al (14) vaccinated 67 anti-HCV reactive patients with HBV vaccine. It was not determined whether the patients had chronic HCV infection or cirrhosis; however, the overall aim of the study was to assess the safety and efficacy of the HAV vaccine. Patients received $20 \mu \mathrm{g}$ of $\mathrm{HBV}$ vaccine at zero, one and six months. One month after the last dose of vaccine, all patients were found to have anti-HBs greater than or equal to $10 \mathrm{mIU} / \mathrm{mL}$ (ie, $100 \%$ vaccine response rate), with a geometric mean concentration of $1260 \mathrm{mIU} / \mathrm{mL}$.

Lee et al (19) evaluated the safety, immunogenicity and possible therapeutic effect of $\mathrm{HBV}$ vaccination in a prospective study. Twenty-six anti-HCV and/or HCV-RNA reactive individuals, considered to have chronic HCV (alanine aminotransferase [ALT] level twice the upper limit of normal on two or more occasions over six months and/or liver biopsy showing evidence of chronic hepatitis) and 35 healthy subjects were immunized with $20 \mu \mathrm{g} \mathrm{HBV}$ vaccine at the regular schedule. They found a slightly lower vaccine response rate one month after the third vaccine dose ( $88.5 \%$ versus $91.4 \%$ in controls). Geometric mean titres of anti-HBs did not differ significantly at seven months $(360 \mathrm{mIU} / \mathrm{mL}$ versus $581 \mathrm{mIU} / \mathrm{mL})$. No significant change of HCV viral load (HCV-RNA level) was found, but ALT levels were significantly lower after three doses of vaccine. 
Another prospective trial by Wiedmann et al (12), of 59 patients with chronic HCV infection and 58 healthy controls, studied the efficacy of the usual administration protocol of $10 \mu \mathrm{g}$ of HBV vaccine. They found a higher rate of nonresponse in the HCV cohort (31\% versus 9\% in controls). However, on high-dose boosting ( $40 \mu \mathrm{g}$ recombinant $\mathrm{HBs} \mathrm{Ag})$, $80 \%$ of HCV nonresponders showed a vaccine response. A subanalysis of the HCV cohort found no significant difference in response to vaccination between patients with or without cirrhosis, although the sample sizes were small.

In contrast, De Maria et al (20) and Idilman et al (21), in a study of 152 chronic HCV patients and 26 controls vaccinated with high-dose vaccine ( $40 \mu \mathrm{g}$ recombinant $\mathrm{HBs} \mathrm{Ag})$ at accelerated intervals (zero, one and two months), found a difference in response in patients with chronic hepatitis with and without histologically verified cirrhosis. A significant difference in vaccine response rate was found when all $\mathrm{HCV}$-positive patients were compared with controls ( $72 \%$ versus $92 \%$, respectively). However, when the HCV cohort was stratified by presence or absence of cirrhosis, the difference in vaccine response was restricted to the cirrhotic patients (54\% HBV vaccine response). Furthermore, nonresponsive HCV patients were given an HBV vaccine booster of $80 \mu \mathrm{g} ; 56 \%$ of cirrhotic and $100 \%$ of noncirrhotic chronic hepatitis individuals responded.

Among 85 anti-HCV-positive patients with chronic HCV infection (confirmed by HCV-RNA), and 46 healthy adult controls vaccinated with $20 \mu \mathrm{g}$ of vaccine at the standard intervals, Mattos et al (22) found that $55.5 \%$ of patients with chronic HCV and $97.8 \%$ of controls responded to the HBV vaccine. No significant difference was found between 65 patients with noncirrhotic chronic hepatitis and 20 patients with cirrhosis. Unfortunately, patients in the present study and previously mentioned studies were not followed for more than three months postvaccination.

Some studies reported the effects of a booster given to nonresponders. Chlabicz et al (23) found that HBV vaccine immunogenicity was decreased in 48 noncirrhotic patients with chronic HCV (confirmed by HCV-RNA) compared with 11 healthy controls, as measured one month after the third dose of $20 \mu \mathrm{g}$ HBV vaccine given according to the usual schedule. The author reported $72.9 \%$ vaccine response in HCV-infected patients compared with $90.9 \%$ in healthy controls. Subjects who had an anti-HBs titre below $10 \mathrm{mIU} / \mathrm{mL}$ at seven or 18 months after the start of their vaccine series were offered a single booster of $20 \mu \mathrm{g}$ recombinant HBV vaccine. Four of 11 initial nonresponders responded to a booster dose given at seven months, and all 11 patients who originally responded to the vaccine series, but had anti-HBs less than $10 \mathrm{mIU} / \mathrm{mL}$ at 18 months, responded to a booster of vaccine.

Only one small study (24) with a longer-term follow-up was identified. It included 36 of the 48 chronic HCV-infected participants in the Chlabicz study described above. Although $76 \%$ of the follow-up group had responded after the original immunization series at seven months, only $36 \%$ maintained anti-HBs levels greater than or equal to $10 \mathrm{mIU} / \mathrm{mL}$ after four years, compared with 90\% (nine of 10) in the control group. Moreover, anti-HBs levels at four years correlated with the individual's initial response. Specifically, only three of $20 \mathrm{HCV}$ patients who had anti-HBs less than $100 \mathrm{mIU} / \mathrm{mL}$ at seven months, had titres greater than or equal to $10 \mathrm{mIU} / \mathrm{mL}$ at four years, despite 19 of them having received vaccine boosters at 18 months. In contrast, of the 16 people in this study who had anti-HBs greater than $99 \mathrm{mIU} / \mathrm{mL}$ at month 7, 10 (63\%) maintained anti-HBs greater than or equal to $10 \mathrm{mIU} / \mathrm{mL}$ after four years. The geometric mean titres were significantly lower in $\mathrm{HCV}$ patients compared with controls $(18.3 \mathrm{mIU} / \mathrm{mL}$ and $156.0 \mathrm{mIU} / \mathrm{mL}$, respectively; $\mathrm{P}<0.05$ ).

In most studies, genotype and viral load were not measured. However, Mattos et al (22) reported better response rates in patients infected with HCV genotype 2 or 3 compared with genotype 1 virus; Elefsiniotis et al (25) also reported genotype 1 to be negatively associated with vaccine response. Mattos et al (22) found that the vaccine response was not related to the serum HCV-RNA concentration. However, Leroy et al (26) found that $64 \%$ of chronic HCV patients responded, but nonresponders had a significantly higher viral load than responders.

Finally, Daryani et al (27) compared the response of standard HBV vaccination between patients with chronic HCV confirmed by HCV-RNA and healthy controls. Although a statistically significant difference in vaccine response was observed between those chronically infected with HCV and controls on univariate analysis ( $73.7 \%$ versus $95 \%$ ), on multivariate analysis, smoking was a significant confounder and when introduced into the model HCV infection, lost its significant correlation with lower antibody response.

The WHO recommends high-dose vaccination $(40 \mu \mathrm{g})$ at zero, one and six months for immunocompromised patients (28), or a four-dose schedule at zero, one, two and 12 months if rapid induction of antibody is desired. HBV vaccination is recommended for persons with HCV infection, but no alteration of the routine dose or schedule is suggested (29).

The Centers for Disease Control and Prevention (USA), recommend vaccination for HCV-positive intravenous drug users and people at risk for sexually transmitted diseases (30). The United States ACIP, in its comprehensive strategy against HBV, does not make specific mention of vaccination policy for chronic HCV-infected individuals (31). However, they acknowledge that higher vaccine doses might be more immunogenic for immunocompromised and hemodialysis patients. Furthermore, they recommend postvaccination serological testing for these populations one to two months after the series to determine the need for booster doses. The American Association for the Study of Liver Diseases makes no specific recommendation for HBV vaccine for people with chronic HCV infection (16).

Finally, Canada's 2006 Immunization Guide recommends HBV vaccine for persons with chronic liver disease, including persons with HCV. These persons should not be at increased risk of infection but may be at risk of more severe acute HBV infection should infection occur. No adjustment of routine HBV immunization schedule or postimmunization serology is recommended.

\section{DISCUSSION}

Superinfection with HBV or HAV can have serious consequences for patients with chronic HCV infection. Reflex testing of sera identified as anti-HCV reactive for anti-HAV and anti-HBs may identify patients who are eligible to receive hepatitis vaccines. The immune response of individuals with cirrhosis is usually reported to be impaired, and this impairment involves both the cellular and humoral immune responses.

No significant difference in HAV seroconversion rates was found in individuals with chronic HCV infection compared with healthy adults following a completed series of HAV 
immunization. Because routine laboratory testing may not detect lower levels of vaccine-induced anti-HAV, postimmunization testing of individuals with $\mathrm{HCV}$ is not recommended. The duration of immunity after a two-dose series of HAV vaccine is not certain, but mathematical models suggest that protection persists for 25 years (32). However, it is not known whether immunity persists for a similar duration in persons with HCV who may achieve lower geometric mean anti-HAV concentrations.

Anti-HAV titres measured before the booster vaccine at six months found that individuals with liver disease had lower geometric mean concentrations of HAV antibody and lower rates of seroconversion. However, following the booster at six months, both studies found no significant differences between any of the study groups and controls in seroconversion rates, although the geometric mean concentrations of antibody were lower for all disease groups.

Liver transplant candidates and recipients, and people with alcoholic liver disease have been recommended modified schedules for HBV vaccination (33). Despite general statements on its importance as a preventive measure against coinfection, there is limited information on $\mathrm{HBV}$ vaccination, specifically for patients with chronic HCV.

In our review, we found considerable variation in terminology of HBV vaccine response, which may be confusing. Vaccine dose and schedules, and classification of participants, also varied, making direct comparison among studies difficult. Some studies enrolled individuals based on anti-HCV results alone, others determined chronic HCV infection by presence of HCV-RNA; in another study, chronic infection was based on ALT level being twice the upper limit of normal and/or liver biopsy. Some studies further divided individuals with chronic HCV into those with cirrhosis and those without. In most studies, confounders known to reduce HBV immunogenicity such as age, smoking and obesity were not considered. Similarly, other potential confounders, such as viral load and genotype, were not reported in many studies.

Antibody response to $\mathrm{HBV}$ vaccination was generally lower in patients with chronic HCV infection compared with controls, indicating some degree of immune compromise in individuals with chronic HCV. Two small studies $(14,19)$ reported no significant difference between HCV and healthy cohorts in response to $\mathrm{HBV}$ vaccination. Daryani et al (27) found that chronic HCV infection lost its significant correlation to vaccine response when smoking was in the model. In one of the larger studies, using a

\section{REFERENCES}

1. Wu HX, Wu J, Wong T, et al. Enhanced surveillance of newly diagnosed hepatitis C virus infection in Canada, 1998 to 2004. Scand J Infect Dis 2006;38:482-9.

2. Vento S, Garofano T, Renzini C, et al. Fulminant hepatitis associated with hepatitis A virus superinfection in patients with chronic hepatitis C. N Engl J Med 1998;29;338:286-90.

3. Neilsen GA, Bodsworth NJ, Watts N. Response to hepatitis A vaccination in human immunodeficiency virus-infected and uninfected homosexual men. J Infect Dis 1997;176:1064-7.

4. Crespo J, Lozano JL, Carte B, de las Heras B, de la Cruz F, Pons-Romero F. Viral replication in patients with concomitant hepatitis B and C virus infections. Eur J Clin Microbiol Infect Dis 1997;16:445-51.

5. Zarski JP, Bohn B, Bastie A, et al. Characteristics of patients with dual infection by hepatitis B and C viruses. J Hepatol 1998;28:27-33.

6. Tyndall MW, Lai C, Ishida T, Shannon K, Cook D, Kerr T. Continued high rates of HIV and hepatitis $\mathrm{C}$ transmission among a vulnerable community in Vancouver: The CHASE project. nonstandard HBV dose and schedule, a significantly lower response was found in individuals with cirrhosis compared with controls and noncirrhotic chronic HCV individuals.

Genotype 1 was found to be related to poorer vaccine response in two studies $(22,25)$; the same genotype, which responds less effectively to $\mathrm{HCV}$ treatment than genotypes 2 and 3 (34). In most studies, genotype was not explored or the majority of patients were type 1 (12). Viral load was found to be associated with immune response in only one of the three studies in which this was adequately considered $(12,22,26)$. Although only $36 \%$ of initial HBV vaccine responders in one study maintained a level of anti-HBs greater than or equal to $10 \mathrm{mIU} / \mathrm{mL}$ at four years, it is not known if previous response indicates long-term protection.

\section{CONCLUSION}

Based on the higher risk of severe disease with HAV or HBV, it is prudent to offer anti-HCV-positive individuals HAV and HBV vaccines. Most leading institutions recommend HAV and HBV vaccination for persons with $\mathrm{HCV}$, but do not advise adjusting vaccine doses or schedules in this population or postimmunization serological testing. Further studies on the nature of immunological memory in HCV-positive populations and the long-term efficacy of HAV and HBV vaccines are needed.

Although data are limited, routine dosing and scheduling of $\mathrm{HAV}$ vaccine appears to be efficacious in the HCV population. Because individuals with $\mathrm{HCV}$ respond well to HAV vaccine, and routine laboratory testing may not detect lower levels of vaccine-induced anti-HAV, postimmunization testing of individuals with $\mathrm{HCV}$ is not recommended.

Several prospective studies have questioned the efficacy of $\mathrm{HBV}$ vaccination for persons with $\mathrm{HCV}$, particularly those with worsening liver disease. The value of high-dose, shortinterval HBV vaccination for patients with $\mathrm{HCV}$ remains indeterminate; further studies may be useful.

Current data support the importance of early HBV vaccination of individuals chronically infected with HCV because they may mount a better response to HBV vaccine before cirrhosis develops. Routine reflex anti-HAV and anti-HBs testing of sera identified as anti-HCV reactive, and adequate follow-up will enable appropriate and timely immunization of these patients. Vaccine response may also be lower in patients with genotype 1 and in those with a high viral load. Serological assessment of $\mathrm{HBV}$ vaccine efficacy enables a booster dose to be given to nonresponders, which has been shown to be effective.

The 13th Annual Canadian Conference on HIV/AIDS Research Montreal, Quebec, May 13-16, 2004.

7. Patrick DM, Tyndall MW, Cornelisse PGA, et al. Incidence of hepatitis $\mathrm{C}$ virus infection among injection drug users during an outbreak of HIV infection. CMAJ 2001;165:889-95.

8. Pasricha N, Datta U, Chawla Y, et al. Poor responses to recombinant $\mathrm{HBV}$ vaccination in patients with HIV infection. Trop Gastroenterol 2005;26:178-82.

9. Corrao G, Calleri M, Zotti M, et al. Immune response to anti-HBV vaccination: Study of conditioning factors. Eur J Epidemiol 1988;4:492-6.

10. Yu AS, Cheung RC, Keeffe EB. Hepatitis B vaccines. Clin Liver Dis 2004;8:283-300.

11. Girndt M, Köhler H. Hepatitis B virus infection in hemodialysis patients. Semin Nephrol. 2002;22:340-50.

12. Wiedmann M, Liebert UG, Oesen U, et al. Decreased immunogenicity of recombinant hepatitis $B$ vaccine in chronic hepatitis C. Hepatology 2000;31:230-4. 
13. De Maria N, Idilman R, Colantoni A, Harig JM, Van Thiel DH. Antibody response to hepatitis $\mathrm{B}$ virus vaccination in individuals with hepatitis C virus infection. Hepatology 2000;32:444-5.

14. Keeffe EB, Iwarson S, McMahon BJ, et al. Safety and immunogenicity of hepatitis A vaccine in patients with chronic liver disease. Hepatology 1998;27:881-6.

15. Lee SD, Chan CY, Yu MI, et al. Safety and mmunogenicity of inactivated hepatitis $A$ vaccine in patients with chronic liver disease. J Med Virol 1997;52:215-8.

16. Strader DB, Wright T, Thomas DL, Seeff LB; American Association for the Study of Liver Diseases. Diagnosis, management, and treatment of hepatitis C. Hepatology 2004;39:1147-71. (Erratum in 2004:40:269).

17. Centers for Disease Control and Prevention. Prevention of Hepatitis A through active or passive immunization: Recommendations of the Advisory Committee on Immunization Practices. <http://www.cdc.gov/mmwr/preview/mmwrhtml/ rr5507a1.htm> (Version current at February 22, 2008).

18. National Advisory Committee on Immunization. Canadian Immunization Guide, 7th edn. Canadian Medical Association, 2006.

19. Lee SD, Chan CY, Yu MI, Lu RH, Chang FY, Lo KJ. Hepatitis B vaccination in patients with chronic hepatitis C. J Med Virol 1999;59:463-8.

20. De Maria N, Idilman R, Colantoni A, Van Thiel DH. Increased effective immunogenicity to high-dose and short-interval hepatitis B virus vaccination in individuals with chronic hepatitis without cirrhosis. J Viral Hepat 2001;8:372-6.

21. Idilman R, De MN, Colantoni A, Nadir A, Van Thiel DH. The effect of high dose and short interval HBV vaccination in individuals with chronic hepatitis C. Am J Gastroenterol 2002;97:435-9.

22. Mattos AA, Gomes EB, Tovo CV, Alexandre CO, Remião JO. Hepatitis $B$ vaccine efficacy in patients with chronic liver disease by hepatitis C virus. Arq Gastroenterol 2004;41:180-4.

23. Chlabicz S, Grzeszczuk A, Lapinski TW. Hepatitis B vaccine immunogenicity in patients with chronic HCV infection at one year follow-up: The effect of interferon-alpha therapy. Med Sci Monit 2002:8:CR379-83.

24. Chlabicz S, Lapinski TW, Grzeszczuk A, Prokopowicz D. Four-year follow up of hepatitis $C$ patients vaccinated against hepatitis B virus. World J Gastroenterol 2005;11:1798-801.
25. Elefsiniotis IS, Vezali E, Kampsoioras K, et al. Immunogenicity of recombinant hepatitis $B$ vaccine in treatment-naive and treatment-experienced chronic hepatitis $\mathrm{C}$ patients: The effect of pegylated interferon plus ribavirin treatment. World J Gastroenterol 2006;12:4420-4.

26. Leroy V, Bourliere M, Durand M, et al. The antibody response to hepatitis $\mathrm{B}$ virus vaccination is negatively influenced by the hepatitis $C$ virus viral load in patients with chronic hepatitis $C$ : A case-control study. Eur J Gastroenterol Hepatol 2002;14:485-9.

27. Daryani NE, Nassiri-Toosi M, Rashidi A, Khodarahmi I. Immunogenicity of recombinant hepatitis $\mathrm{B}$ virus vaccine in patients with and without chronic hepatitis $\mathrm{C}$ virus infection: A case-control study. World J Gastroenterol 2007;13:294-8.

28. World Health Organization. Hepatitis B. <http://www.who.int/ csr/disease/hepatitis/HepatitisB_whocdscsrlyo2002_2.pdf> (Version current at February 22, 2008).

29. World Health Organization. Hepatitis C. <http://www.who.int/csr/ disease/hepatitis/Hepc.pdf> (Version current at February 22, 2008).

30. Centers for Disease Control and Prevention. Recommendations for prevention and control of Hepatitis $\mathrm{C}$ virus (HCV) infection and HCV-related chronic disease. < http://www.cdc.gov/mmwr/ preview/mmwrhtml/00055154.htm> (Version current at February 22, 2008).

31. Centers for Disease Control and Prevention. A comprehensive immunization strategy to eliminate transmission of hepatitis B virus infection in the United States. Recommendations of the Advisory Committee on Immunization Practices (ACIP) Part II: Immunization of adults. <http://www.cdc.gov/mmwR/PDF/rr/ rr5516.pdf $>$ (Accessed November 1, 2007).

32. Van Damme P, Van Herck K. A review of the long-term protection after hepatitis A and B vaccination. Travel Med Infect Dis 2007;5:79-84.

33. Reiss G, Keeffe EB. Review article: Hepatitis vaccination in patients with chronic liver disease. Aliment Pharmacol Ther 2004;19:715-27.

34. Sherman M, Bain V, Villeneuve JP, et al. Management of viral hepatitis: A Canadian consensus conference, 2004. $<$ http://www.hepatology.ca/cm/FileLib/ViralHepatitisCanadian Consensus2004.pdf> (Version current at February 22, 2008). 


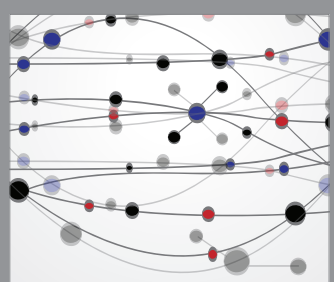

The Scientific World Journal
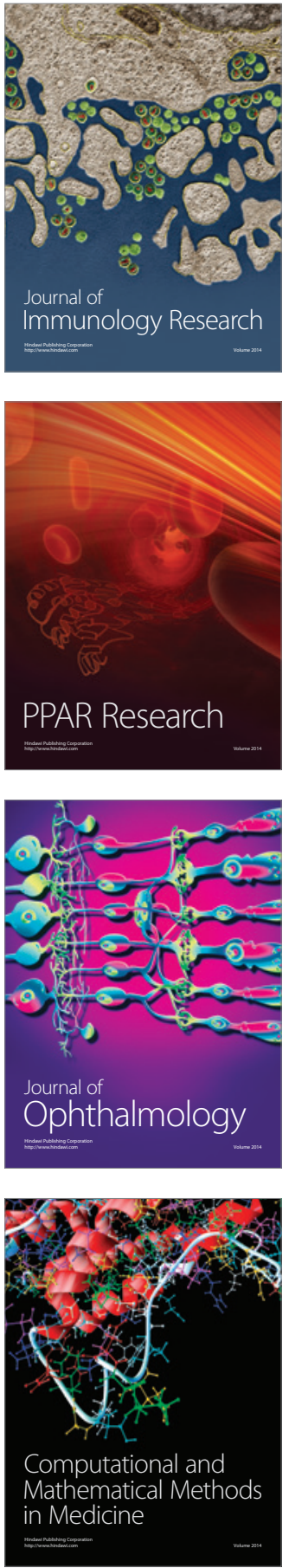

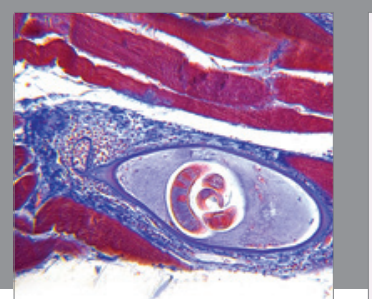

Gastroenterology Research and Practice

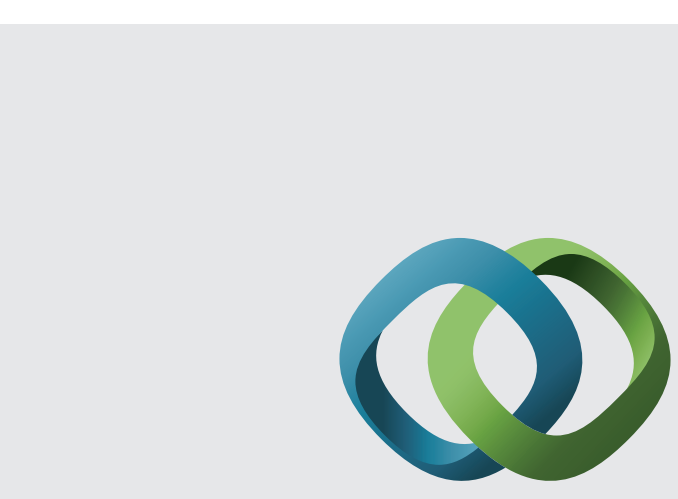

\section{Hindawi}

Submit your manuscripts at

http://www.hindawi.com
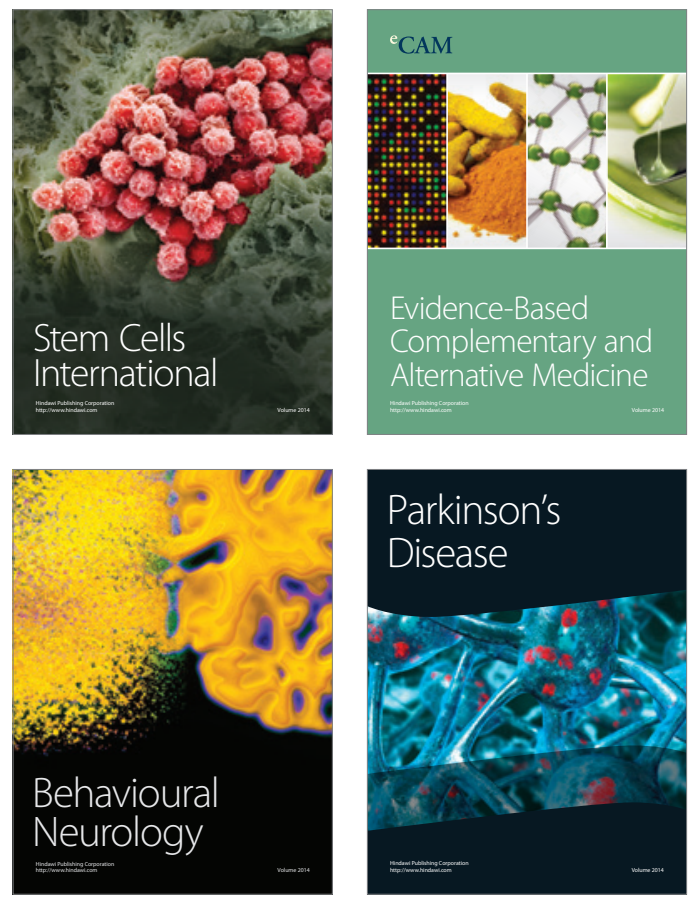
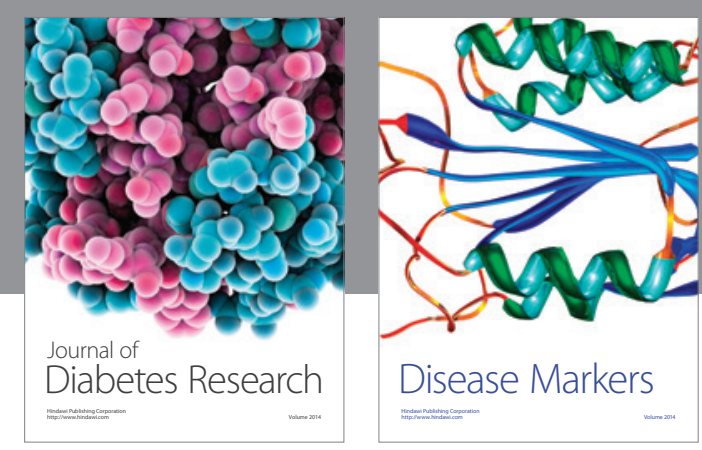

Disease Markers
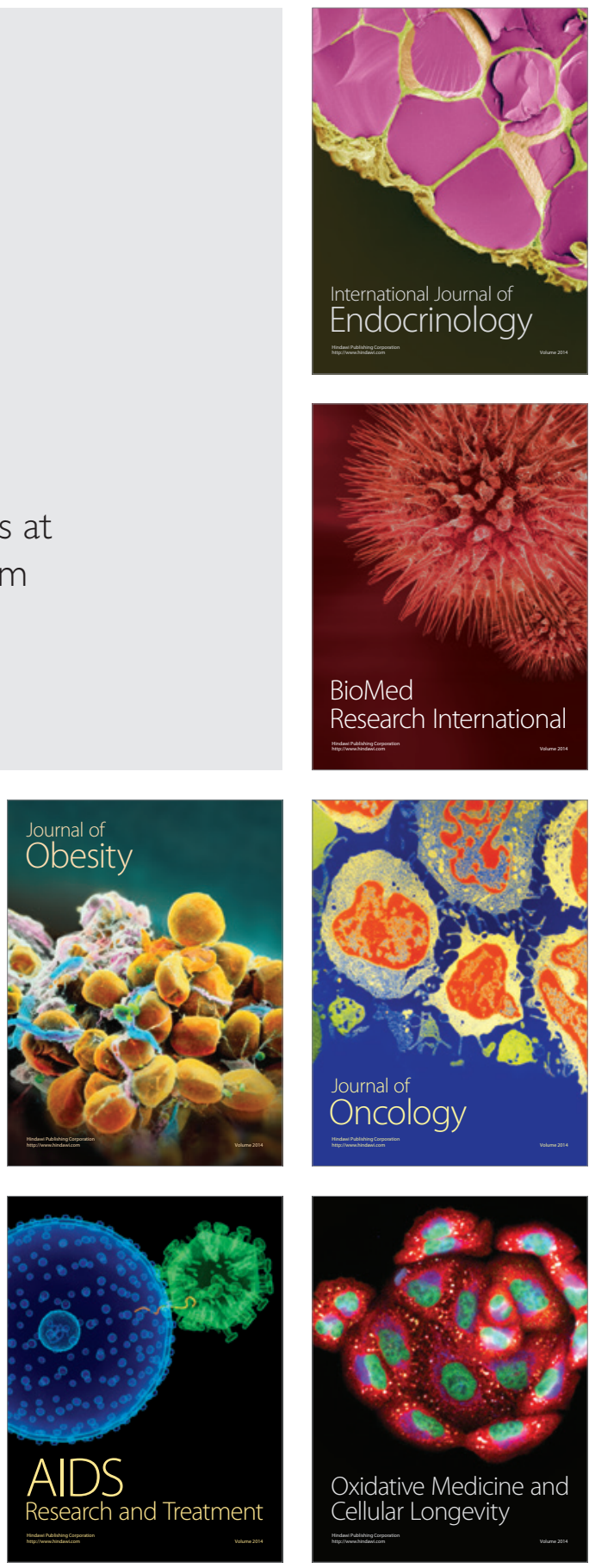